\title{
Transcriptome Profiles in Pig Spleens with Divergent Peripheral Blood T Lymphocyte Subsets
}

\author{
Jingen Xu' ${ }^{1}$, Yang Liu ${ }^{2}$, Erhui Jin', Youfang Gu${ }^{1}$, Qin Zhang ${ }^{3}$ and Shenghe $\mathbf{L i}^{1, *}$ \\ ${ }^{1}$ College of Animal Science, Anhui Science and Technology University, Fengyang \\ 233100, China \\ ${ }^{2}$ College of Animal Science and Technology, Nanjing Agricultural University, Nanjing \\ 210095, China \\ ${ }^{3}$ College of Animal Science and Technology, China Agricultural University, Beijing \\ 100193, China
}

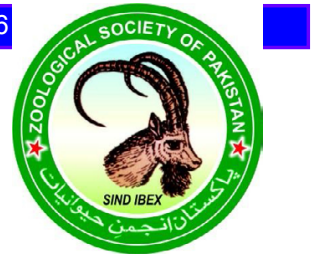

CrossMark

\begin{abstract}
A B S T R A C T
Divergent hematological traits in swine may confer physiological differences, so we studied transcriptome profiles in spleens of Yorkshire pigs with different peripheral blood T lymphocyte subsets. The results showed that 2050 differentially expressed transcripts were identified, with 1554 up-regulated and 496 up-regulated in high and low T lymphocyte groups, respectively. Among differentially expressed genes, $I L 1 B, I L 17 F$, IL6R, CXCL2, CCL20 and CCL25 were selected based on their immunological functions and $C D 8 B$ and $C D 81$ may contribute to variations of blood T lymphocyte subsets. Gene ontology analysis revealed that differential gene expression involved in biological processes, including the G-protein coupled receptor protein signaling pathway, intrinsic to membrane, cell junction and ion transport. KEGG pathway analysis showed that the neuroactive ligand-receptor interaction was significantly enriched. The results offer a foundation for exploration of immune functions and genetic control of peripheral blood $\mathrm{T}$ lymphocyte subsets. Also, several differentially expressed immune-related genes may be candidate genes for disease resistance breeding in pigs.
\end{abstract}

\author{
Article Information \\ Received 07 October 2017 \\ Revised 03 November 2017 \\ Accepted 13 November 2017 \\ Available online 31 August 2018 \\ Authors' Contribution \\ $\mathrm{JX}$ and SL conceived and designed \\ the experiments; YL, EJ, YG and \\ $Q Z$ contributed reagents, materials, \\ and analysis tools; JX wrote the \\ manuscript. \\ Key words \\ Pig, Microarray, Peripheral blood \\ T lymphocyte subsets, Spleen, Gene \\ expression.
}

\section{INTRODUCTION}

$\mathrm{M}$ odification of blood components such as leukocytes can arise from health changes, so hematological biochemistry is often a proxy for evaluating immune function. Differences in hematological indices may indicate immune resistance, so the blood immune traits have been integrated into breeding approaches for selecting resistance in pigs (Borjigin et al., 2016). Accordingly, identifying genomic regulation of hematological parameters can contribute to the study of anti-disease breeding in swine.

As an immune constituent, T lymphocytes are essential for adaptive immunity against the invasion of pathogens. Four T lymphocyte subsets: $\mathrm{CD} 4^{-} \mathrm{CD} 8^{-}, \mathrm{CD} 4^{+} \mathrm{CD} 8^{+}$, $\mathrm{CD}^{+}{ }^{+} \mathrm{CD} 8^{-}$and $\mathrm{CD} 4{ }^{-} \mathrm{CD}^{+}$cells exist in porcine peripheral blood and lymphoid tissues (Saalmüller et al., 1987). Proportions of T lymphocyte subsets in peripheral blood change when pigs are challenged with different pathogens (Darwich et al., 2002; Jonasson et al., 2004). Therefore, hematological indices consisting of $\mathrm{T}$ lymphocyte subsets can be used to reflect immune capacity. Findings from

\footnotetext{
* Corresponding author: lish@ahstu.edu.cn

0030-9923/2018/0006-2079 \$ 9.00/0

Copyright 2018 Zoological Society of Pakistan
}

previous studies indicate that blood $\mathrm{T}$ lymphocyte subsets are genetically regulated in mice and humans (Damoiseaux et al., 1999; Ahmadi et al., 2001). In swine, heritability of blood $\mathrm{T}$ lymphocyte subsets was reported to reach moderate to high values (Clapperton et al., 2008), indicating that this trait is also genetically controlled and may be selected to improve immunity. Considering the importance of peripheral blood $\mathrm{T}$ lymphocyte subsets in immunology, QTL mapping and genome wide association analyses were carried out to investigate genetic variations of these hematological indices in pigs ( $\mathrm{Lu}$ et al., 2011; 2012), but molecular mechanisms regulating blood $T$ lymphocyte subsets are unclear and causal genes involved in trait modulation require more work. Additionally, the immune role of blood $\mathrm{T}$ lymphocyte subsets is not clearly and how they reflect immunity is uncertain. Therefore, it is essential to assess peripheral blood $\mathrm{T}$ lymphocyte subsets to know whether manipulation of them may enhance porcine disease resistance.

As the spleen is an important peripheral immune organ, its transcriptome characteristics can be used to evaluate immune responses of pigs infected with different pathogens (Chen et al., 2009; Li et al., 2010; Zhang et al., 2017). The spleen also has functions involving in filtering the blood and removing old erythrocytes (Mebius and Kraal, 
2005). Hematological parameters are indirect indicators for reflecting health, and splenic changes may indicate immune capacity more than blood biochemistry. To date, few reports are available to describe gene transcriptome features in immune tissues of swine with different blood indices. To address this, we used microarray to investigate splenic transcriptome profiles of Yorkshire pigs with divergent peripheral blood $\mathrm{T}$ lymphocyte subsets, which was to evaluate immune function of this hematological trait and identify differentially expressed immune-related genes for porcine disease resistance breeding.

\section{MATERIALS AND METHODS}

\section{Experimental animals and blood indices measurement}

This study was approved by the Animal Ethics Committee of China Agricultural University. The samples of 8 Yorkshire pigs used in our study were from our previous experimental populations raised under same indoor conditions in the Changping experimental farm of Chinese Academy of Agricultural Sciences (Lu et al., 2012). First blood samples were collected from 20 -day-old piglets with no clinical symptoms, and these were baseline hematological indices. On the second day, piglets were firstly inoculated with an immunologic stimulant, classical swine fever (CSF) vaccine (rabbit origin, Harbin Veterinary Research Institute, China). Second blood samples were collected from healthy pigs on day 35 , and piglets were slaughtered and spleen tissue was harvested. Peripheral blood samples were directly injected into vacuum tubes containing EDTA, and spleen samples were quickly frozen in liquid nitrogen.

Peripheral blood $\mathrm{T}$ lymphocyte subsets were automatically measured using flow cytometry as described by Lu et al. (2011). Seven blood indices were composed of T lymphocyte subsets, including the percentage of CD4 $\mathrm{CD} 8^{-}, \mathrm{CD} 4^{+} \mathrm{CD} 8^{+}, \mathrm{CD} 4^{+} \mathrm{CD} 8^{-}, \mathrm{CD} 4^{-} \mathrm{CD} 8^{+}, \mathrm{CD} 4^{+}, \mathrm{CD} 8^{+}$ cells, and the ratio of $\mathrm{CD}^{+} / \mathrm{CD}^{+}$.

\section{Statistical analysis of blood indices}

According to the significant differences of partial blood $\mathrm{T}$ lymphocyte subset indices, eight female piglets were selected and equally divided into two groups (Table I). The high group was defined as pigs with higher $\mathrm{CD} 4^{+}$ related indices (including $\mathrm{CD} 4^{+} \mathrm{CD} 8^{-}, \mathrm{CD}^{+}$and $\mathrm{CD}^{+} /$ $\mathrm{CD} 8^{+}$) compared to the low group (the control group). Statistical analysis was carried out using the GLM (general linear model) procedure of SAS 9.0, and the model was as follows: $y=\mu+g+b f+e$, where $y$ is the blood index on day $35, \mu$ is the overall mean, $g$ is the effect of group, $b$ is the regression coefficient, $f$ is the blood index on day 20 , and e is the residual error. The significant and extreme differences were set at 0.05 and 0.01 , respectively.

\section{RNA extraction and microarray hybridization}

Total RNA was extracted from porcine spleen using Trizol reagent (Life Technologies, Carlsbad, USA). RNA quality and purity were checked using an Agilent Bioanalyzer 2100 (Agilent Technologies, Santa Clara, USA), and the qualified criteria were RNA integrity number $>7$ and $28 \mathrm{~S} / 18 \mathrm{~S}>0.7$.

Microarray hybridization was conducted by the Shanghai Biotechnology Corporation. According to the manufacturer's instructions, 8 RNA samples were purified using RNeasy mini kit (QIAGEN, GmbH, Germany) and RNase-Free DNase Set (QIAGEN, GmbH, Germany), and then samples were amplified and labeled with Low Input Quick Amp Labeling Kit, One-Color (Agilent Technologies, Santa Clara, USA). Next, labeled cRNA was purified again and each sample $(1.65 \mu \mathrm{g}$ cRNA) was subsequently hybridized with Agilent Porcine Oligo Microarray Slide (4x 44K) using a Gene Expression Hybridization Kit. After $17 \mathrm{~h}$ of hybridization at $65^{\circ} \mathrm{C}$, each slide was washed with Gene Expression Wash Buffer Kit.

\section{Microarray data analysis}

Slides were scanned on an Agilent Microarray Scanner, and raw data were extracted by Feature Extraction software 10.7 and normalized using Gene Spring Software 11.0 (Agilent Technologies, Santa Clara, USA). Although the 8 pigs were selected with partial divergent blood indices, they were kept under normal conditions that reduced fold change (FC) of differentially expressed genes (DEGs). To comprehensively understand transcription profiles, FC $>$ 1.5 and $\mathrm{P}<0.05$ were selected as screening criteria for DEGs using Significance Analysis of Microarrays.

DAVID Bioinformatics Resources 6.7 (http:// david.abcc.ncifcrf.gov/home.jsp) was used for functional enrichment analysis of DEGs, including Gene Ontology (GO) and Kyoto Encyclopedia of Genes and Genomes (KEGG) pathway analysis.

\section{Quantitative real time $P C R$}

Total RNA distracted from spleens was measured using a NanoDrop ${ }^{\mathrm{TM}} 2000$ spectrophotometer (Thermo Scientific, Wilmington, USA). According to the instructions of PrimerScript RT reagent Kit (Takara Biotechnology, Dalian, China), $1 \mu \mathrm{g}$ of total RNA was reverse transcribed into cDNA in a $20 \mu \mathrm{L}$ volume.

To verify the microarray data, expression of 7 genes was measured by quantitative real time PCR (qRT-PCR). Three representative DEGs (ILIB and CXCL2 were upregulated, and $C D 8 B$ was down-regulated) were chosen 
based on their immune function; the other 4 non-DEGs (CD4, CD8A, DQA1 and DQB1) were selected for having vital roles in differentiation and activation of $\mathrm{T}$ lymphocyte subsets. Intron-spanning primers of the 7 genes were designed by Oligo6.0 software according to the corresponding mRNA sequences in Genbank (Table II), and primers of the internal reference gene (B-actin) were cited from Zhou et al. (2012). The qRT-PCR reaction system included $1 \mu \mathrm{L}$ of cDNA, $10 \mu \mathrm{L}$ of $2 x$ SYBR green I mixture, $1 \mu \mathrm{L}$ each of primers and $7 \mu \mathrm{L}$ of $\mathrm{H}_{2} \mathrm{O}$. The reaction conditions were an initial denaturation at $94{ }^{\circ} \mathrm{C}$ for $10 \mathrm{~min}, 40$ cycles at $94{ }^{\circ} \mathrm{C}$ for $15 \mathrm{~s}, 60{ }^{\circ} \mathrm{C}$ for $15 \mathrm{~s}$ and $72{ }^{\circ} \mathrm{C}$ for $15 \mathrm{~s}$. Standard curves were made using serially diluted cDNA to ensure amplification efficiency, and melting curves were generated to confirm specificity of amplification. Each cDNA sample was independently performed in triplicate using a LightCycler 480 instrument (Roche Diagnostics, Mannheim, Germany), and relative gene expression was calculated by the $2^{-\Delta \Delta \mathrm{Ct}}$ method (Livak and Schmittgen, 2001). Differences in expression level of 7 genes between the two groups were analyzed using the Student's $t$-test.

\section{RESULTS}

\section{Differentially expressed genes}

Based on the differences of peripheral blood $\mathrm{T}$ lymphocyte subsets, 8 Yorkshire piglets were equally divided into two groups (Table I). Then, an Agilent Porcine Genome Array including 43603 cDNA probes was used to screen transcriptome profiles of spleens in the two group pigs. The results showed that the differential expression of 2050 transcripts was more than 1.5 times (P $<0.05$ ), with 1554 up-regulated and 496 down-regulated in the high group compared to the low group. Clustering analysis confirmed that the differential gene sets agreed with phenotype grouping based on blood $\mathrm{T}$ lymphocyte subsets (Fig. 1).

Only 545 differentially expressed probes were annotated (representing 498 unique genes), whereas functions of the remaining 1505 probes were unknown. Some immune-related differentially expressed genes were identified in this study (Table III), suggesting that they may reflect differences in immune responses and may be associated with divergent hematological indices.

Table I.- Comparison of peripheral blood $\mathrm{T}$ lymphocyte subsets in the high and low group pigs.

\begin{tabular}{lll}
\hline Index & High $(\mathbf{N}=\mathbf{4})$ & Low $(\mathbf{N}=\mathbf{4})$ \\
\hline $\mathrm{CD}^{-} \mathrm{CD}^{-}(\%)$ & $24.65 \pm 7.93$ & $28.38 \pm 9.18$ \\
$\mathrm{CD}^{+}{ }^{+} \mathrm{CD} 8^{+}(\%)$ & $15.50 \pm 2.98$ & $12.88 \pm 2.59$ \\
$\mathrm{CD}^{+}{ }^{+} \mathrm{CD} 8^{-}(\%)$ & $23.28 \pm 3.83^{\mathrm{A}}$ & $5.83 \pm 0.79^{\mathrm{B}}$ \\
$\mathrm{CD} 4^{-} \mathrm{CD} 8^{+}(\%)$ & $36.60 \pm 11.22$ & $52.93 \pm 6.50$ \\
$\mathrm{CD}^{+}(\%)$ & $38.78 \pm 6.37^{\mathrm{A}}$ & $18.70 \pm 3.16^{\mathrm{B}}$ \\
$\mathrm{CD}^{+}(\%)$ & $52.10 \pm 10.43$ & $65.80 \pm 8.37$ \\
$\mathrm{CD}^{+} / \mathrm{CD} 8^{+}$ & $0.78 \pm 0.22^{\mathrm{A}}$ & $0.28 \pm 0.02^{\mathrm{B}}$ \\
\hline
\end{tabular}

Data in the table are means \pm standard deviation. In the same row, values with the different capital letter is very significant difference $(\mathrm{P}<0.01)$, while values with no letter is no significant difference $(\mathrm{P}>0.05)$

Table II.- Primers used for detecting gene expression levels by quantitative real time PCR.

\begin{tabular}{|c|c|c|c|}
\hline Gene & Primer sequence $\left(5^{\prime}-3{ }^{\prime}\right)$ & Annealing temperature $\left({ }^{\circ} \mathrm{C}\right)$ & Product size (bp) \\
\hline \multirow[t]{2}{*}{ CD4 } & F: GAGCGGATGTCTCAGATCAAG & 60 & 93 \\
\hline & R: GCCTCAGGTGAGGGAATAGTT & & \\
\hline \multirow[t]{2}{*}{$C D 8 B$} & F: CTTTGGGAAGGGAACTCGG & 60 & 107 \\
\hline & R: CCAGGTTTGGTAATCGGCAT & & \\
\hline \multirow[t]{2}{*}{$I L 1 B$} & F: AGTGGAGAAGCCGATGAAGA & 60 & 138 \\
\hline & R: ACGTTGGCATCACAGACAAA & & \\
\hline \multirow[t]{2}{*}{ CXCL2 } & F: CTGTGACCAAACGGAAGTCA & 60 & 121 \\
\hline & R: TCAGTTGGCACTGCTCTTGT & & \\
\hline \multirow[t]{2}{*}{$D Q A 1$} & F: ACCTGGAGAAGAAGGAGACTG & 60 & 190 \\
\hline & R: ATCACTGGAGACTTGGGAAAC & & \\
\hline \multirow[t]{2}{*}{$D Q B 1$} & F: AGATAGAGGAAGGCACGACC & 60 & 136 \\
\hline & R: ACTTTCACCTGGCTTGGATAG & & \\
\hline \multirow[t]{2}{*}{$C D 8 A$} & F: GTCATCACCATCATCTGCCAC & 60 & 123 \\
\hline & R: GGGCATGTCGCCATGTTAG & & \\
\hline
\end{tabular}



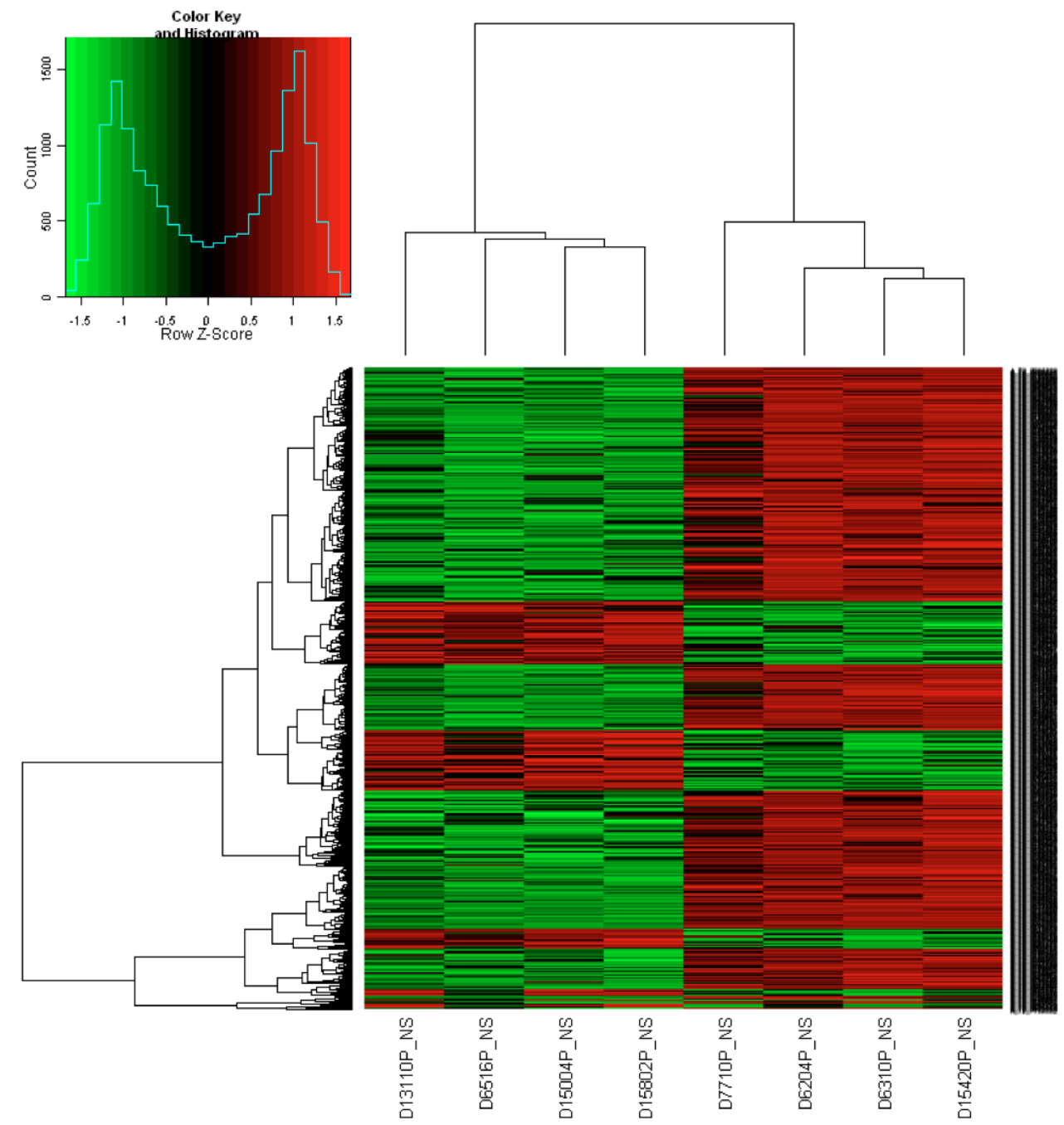

Fig. 1. Hierarchical cluster analysis of differentially expressed transcripts.

Table III.- Differentially expressed genes related to immune response.

\begin{tabular}{llll}
\hline Gene & Fold change & P-value & Note \\
\hline$I L 1 B$ & 1.98 & 0.0077 & up-regulation \\
$I L 6 R$ & 1.66 & 0.0007 & up-regulation \\
$I L 17 F$ & 1.83 & 0.0001 & up-regulation \\
$C X C L 2$ & 1.70 & 0.0298 & up-regulation \\
$C C L 20$ & 1.65 & 0.0374 & up-regulation \\
$C C L 25$ & 1.59 & 0.0008 & up-regulation \\
$C D 81$ & 2.67 & 0.0001 & up-regulation \\
$C D 8 B$ & 0.38 & 0.0142 & down-regulation \\
\hline
\end{tabular}

Fold change $>1.50$, means up-regulated in the high group versus the low group; fold change $<0.67$, means down-regulated in the high group versus the low group.
Functional annotation of differentially expressed genes

To understand the biological implications of microarray data, functional annotation of differentially expressed genes was performed using DAVID, including GO and pathway enrichment analysis. GO analysis showed that G-protein coupled receptor protein signaling pathway, intrinsic to membrane, cell junction and ion transport were significantly enriched, and KEGG analysis indicated that neuroactive ligand-receptor interaction was the only significantly enriched pathway (Table IV). Besides, several specific GO terms and pathways related to immune responses were also listed in Table IV, although they were not significantly enriched.

Gene expression by quantitative real time PCR

To validate microarray results, mRNA levels for 7 genes were examined by qRT-PCR using the same spleen 
Table IV.- GO term and pathway analysis of differentially expressed genes.

\begin{tabular}{|c|c|c|c|c|}
\hline Category & GO term and pathway & Enrichment score & Counts & P-value \\
\hline GOTERM_BP_FAT & G-protein coupled receptor protein signaling pathway & 1.97 & 17 & 0.0004 \\
\hline GOTERM_CC_FAT & Intrinsic to membrane & 1.61 & 54 & 0.015 \\
\hline GOTERM_CC_FAT & Cell junction & 0.81 & 8 & 0.029 \\
\hline GOTERM_BP_FAT & Ion transport & 0.65 & 14 & 0.027 \\
\hline KEGG_PATHWAY & Neuroactive ligand-receptor interaction & 1.97 & 16 & 0.0008 \\
\hline GOTERM_MF_FAT & Chemokine receptor binding & 0.16 & 3 & 0.46 \\
\hline GOTERM_MF_FAT & Cytokine activity & 0.16 & 4 & 0.90 \\
\hline GOTERM_BP_FAT & Immune response & 0.16 & 5 & 0.98 \\
\hline KEGG_PATHWAY & Chemokine signaling pathway & 0.16 & 4 & 0.83 \\
\hline
\end{tabular}

Table V.- Comparison of the results from microarray analysis and quantitative real time PCR.

\begin{tabular}{lllll}
\hline Probe & Microarray (FC) & Gene & GenBank accession & qRT-PCR (FC) \\
\hline A_72_P463511 & $1.98^{*}$ & $I L 1 B$ & NM_001005149 & $1.96(\mathrm{P}=0.288)$ \\
A_72_P732383 & $1.70^{*}$ & CXCL2 & NM_001001861 & $1.76(\mathrm{P}=0.049)$ \\
A_72_P672583 & 1.35 & $D Q B 1$ & NM_001113694 & $1.39(\mathrm{P}=0.141)$ \\
A_72_P077421 & 1.18 & $C D 4$ & NM_001001908.1 & $1.30(\mathrm{P}=0.200)$ \\
A_72_P765361 & 0.93 & $D Q A 1$ & AY285932 & $1.17(\mathrm{P}=0.193)$ \\
A_72_P077466 & 0.55 & $C D 8 A$ & NM_001001907 & $0.53(\mathrm{P}=0.177)$ \\
A_72_P088456 & $0.38^{*}$ & $C D 8 B$ & NM_213762 & $0.56(\mathrm{P}=0.060)$ \\
\hline
\end{tabular}

$* \mathrm{P}<0.05$; FC: fold change.

samples. As shown in Table $\mathrm{V}$, the fold changes in gene expression levels detected by qRT-PCR were consistent with microarray outcomes, indicating that microarray data in our study were reliable.

\section{DISCUSSION}

Hematological variables may reflect immune capacity to resist pathogens. However, specific ranges of hematological indices have not been determined. Identification of genetic regulators of hematological traits can contribute to livestock breeding for disease resistance. Because peripheral blood $\mathrm{T}$ lymphocyte subsets vary with immune status, they may be a representative trait in immunology. To address this, we triggered swine immune reactions by vaccinating pigs with a CSF vaccine, and assessed blood biochemistry and alterations in immune organs to reveal potential markers of disease resistance. Specifically, we characterized splenic transcriptome profiles in pigs with different peripheral blood $\mathrm{T}$ lymphocyte subsets to better understand immunity and disease resistance.

Microarray data indicate that differences in the splenic transcriptome of pigs carrying divergent peripheral blood $\mathrm{T}$ lymphocyte subsets were genetically based and these differences were associated with immunity. Of the 2050 differentially expressed probes identified in the two groups with divergent blood indices, $26.6 \%$ were annotated. These data were similar to the report that most DEGs were not annotated in peripheral blood leukocytes of pigs infected with CSF virus (Shi et al., 2009). The functional annotation of most differentially expressed probes is unknown, but they may still offer insight into transcription profiles in the spleen with divergent hematological parameters. Gladue et al. (2010) reported cytokine gene expression (e.g. ILIB and CXCL2) were up-regulated in macrophages isolated from peripheral blood of pigs after CSF virus infection. We observed that several immune genes were differentially expressed in spleen after pigs inoculated with CSF vaccine, including interleukins (IL1B and $I L 17 F)$, interleukin receptor (IL6R) and chemokines (CXCL2, CCL20 and CCL25), suggesting that these DEGs were closely related to phenotypic differences. IL1B was up-regulated in swine alveolar macrophages after CSF virus infection (Lin et al., 2014), and CCL20 co-administration with a DNA vaccination had enhanced 
immunoregulation against the CSF virus (Tarradas et al., 2011). Accordingly, these DEGs directly participated in immune reactions and can be promising functional genes for porcine disease resistance.

In the present study, differentially expressed genes involved in GO terms and pathways were analyzed using DAVID. Among the significantly enriched biological processes, G-protein coupled receptor protein signaling pathway was enriched in human renal cell carcinoma (Liu et al., 2015), and ion transport was impaired in human microscopic colitis (Barmeyer et al., 2012), indicating that these two GO terms might be relevant to immune response. Intrinsic to membrane and cell junction were also clustered, suggesting that different blood $\mathrm{T}$ lymphocyte subsets were associated with changes of cellular components and connections in the spleen. KEGG analysis revealed that the neuroactive ligand-receptor interaction pathway was significantly enriched. It was reported that the neuroactive ligand-receptor interaction pathway was associated with human astrocyte response to H5N1 (Lin et al., 2015), indicating an association with immune function. In addition, several immune related biological processes were clustered but this did not reach statistical significance, including chemokine receptor binding, cytokine activity, immune response and chemokine signaling pathway. Genetic variations occurred in different individuals after vaccination (Glass, 2004), suggesting that increased immunity may be selected using genetic improvement. We found that most genes with increased expression were in the high group, implying that in pigs with divergent $\mathrm{CD}^{+}$blood indices may be related to differences in vaccine response. Cytokines recruit lymphocytes to the site of immune reaction to activate and regulate antigen response. Several DEGs are cytokines expressed more abundantly in the spleen of high group pigs, so these up-regulated genes may be beneficial to promoting swine antigen response. These data suggest an immune function of blood T lymphocyte subsets, but higher or lower levels of these hematological indices stand for better immunity need further research.

$\mathrm{T}$ cell activation exists in peripheral blood and spleen during human suffered with hepatosplenic schistosomiasis mansoni (Teixeira-Carvalho et al., 2002). Moreover, a strong concordance has been reported between transcriptome patterns in the spleen and peripheral blood leukocytes in chicken infected with pathogenic Escherichia coli (Sandford et al., 2012). T lymphocytes are distributed in peripheral blood and lymphoid tissues, and differences in $\mathrm{T}$ cell components in blood may be associated with changes in the spleen after piglets are stimulated with the CSF vaccine. Therefore, analyzing splenic transcriptome profiles in pigs with divergent blood $\mathrm{T}$ lymphocyte subsets may help to identify potential DEGs correlated with variations in this hematological trait. Specifically, we identified $C D 8 B$ and $C D 81$ genes, which participating in $\mathrm{T}$ cell proliferation. $\mathrm{CD} 8 \mathrm{~B}$ molecule contributes to $\mathrm{CD}^{+}$cell development (Bosselut et al., 2000), and CD81 protein is involved in activation, proliferation and differentiation of $\mathrm{T}$ cells (Levy et al., 1998), indicating that the 2 DEGs (CD8B down-regulation and CD81 upregulation) may be associated with blood $\mathrm{T}$ lymphocyte subsets. To understand genetic control and identify causal genes underlying peripheral blood $\mathrm{T}$ lymphocyte subset variations, transcriptome in porcine blood should be investigated in future studies.

\section{CONCLUSIONS}

Exploring whole gene expression in pig spleens to study divergent peripheral blood $\mathrm{T}$ lymphocyte subsets, we provide a foundation for understanding the immunological role of this hematological trait. Several immune-related DEGs (IL1B, IL17F, IL6R, CXCL2, CCL20 and CCL25) were identified and may be promising candidate genes for porcine disease resistance breeding, and $C D 8 B$ and $C D 81$ genes were identified which may be associated with variations of peripheral blood T lymphocyte subsets.

\section{ACKNOWLEDGEMENTS}

This work was supported by the Provincial Natural Science Research Project of Anhui University (KJ2016A180 and KJ2017ZD43), the Science and Technology Key Project of Anhui Province (16030701066), and the National Natural Science Foundation of China (31402154).

Statement of conflict of interest

Authors have declared no conflict of interest.

\section{REFERENCES}

Ahmadi, K.R., Hall, M.A., Norman, P., Vaughan, R.W., Snieder, H., Spector, T.D. and Lanchbury, J.S., 2001. Genetic determinism in the relationship between human $\mathrm{CD}^{+}$and $\mathrm{CD} 8^{+} \mathrm{T}$ lymphocyte populations? Genes Immun., 2: 381-387. https:// doi.org/10.1038/sj.gene.6363796

Barmeyer, C., Erko, I., Fromm, A., Bojarski, C., Allers, K., Moos, V., Zeitz, M., Fromm, M. and Schulzke, J.D., 2012. Ion transport and barrier function are disturbed in microscopic colitis. Annl. N. Y. Acad. Sci., 1258: 143-148. https://doi.org/10.1111/j.17496632.2012.06631.x 
Borjigin, L., Shimazu, T., Katayama, Y., Li, M., Satoh, T., Watanabe, K., Kitazawa, H., Roh, SG., Aso, H., Katoh, K., Uchida, T., Suda, Y., Sakuma, A., Nakajo, M. and Suzuki, K., 2016. Immunogenic properties and mycoplasmal pneumonia of swine (MPS) lung lesions in Large White pigs selected for higher peripheral blood immune capacity. Anim. Sci. J., 87: 638-645. https://doi.org/10.1111/asj.12471 https://doi.org/10.1111/asj.12529

Bosselut, R., Kubo, S., Guinter, T., Kopacz, J.L., Altman, J.D., Feigenbaum, L. and Singer, A., 2000. Role of CD8 $\beta$ domains in CD8 coreceptor function: importance for MHC I binding, signaling, and positive selection of $\mathrm{CD}^{+} \mathrm{T}$ cells in the thymus. Immunity, 12: 409-418. https://doi.org/10.1016/ S1074-7613(00)80193-4

Chen, H., Li, C., Fang, M., Zhu, M., Li, X., Zhou, R., Li, K. and Zhao S., 2009. Understanding Haemophilus parasuis infection in porcine spleen through a transcriptomics approach. BMC Genomics, 10: 64. https://doi.org/10.1186/1471-2164-10-64

Clapperton, M., Glass, E.J. and Bishop, S.C., 2008. Pig peripheral blood mononuclear leucocyte subsets are heritable and genetically correlated with performance. Animal, 2: 1575-1584. https://doi. org/10.1017/S1751731108002929

Damoiseaux, J.G., Cautain, B., Bernard, I., Mas, M., van Breda Vriesman, P.J., Druet, P., Fournié, G. and Saoudi, A., 1999. A dominant role for the thymus and MHC genes in determining the peripheral CD4/CD8 T cell ratio in the rat. J. Immunol., 163: 2983-2988.

Darwich, L., Segalés, J., Domingo, M. and Mateu, E., 2002. Changes in $\mathrm{CD}^{+}, \mathrm{CD}^{+}, \mathrm{CD}^{+} \mathrm{CD}^{+}$, and immunoglobulin $\mathrm{M}$-positive peripheral blood mononuclear cells of postweaning multisystemic wasting syndrome-affected pigs and age-matched uninfected wasted and healthy pigs correlate with lesions and porcine circovirus type 2 load in lymphoid tissues. Clin. Diagn. Lab. Immunol., 9: 236-242. https://doi.org/10.1128/CDLI.9.2.236242.2002

Gladue, D.P., Zhu, J., Holinka, L.G., Fernandezsainz, I., Carrillo, C., Prarat, M.V., O’Donnell, V. and Borca M.V., 2010. Patterns of gene expression in swine macrophages infected with classical swine fever virus detected by microarray. Virus Res., 151: 1018. https://doi.org/10.1016/j.virusres.2010.03.007

Glass, E.J., 2004. Genetic variation and response to vaccines. Anim. Hlth. Res. Rev., 5: 197-208. https:// doi.org/10.1079/AHR200469

Jonasson, R., Johannisson, A., Jacobson, M., Fellström,
C. and Jensen-Waern, M., 2004. Differences in lymphocyte subpopulations and cell counts before and after experimentally induced swine dysentery. J. med. Microbiol., 53: 267-272. https://doi. org/10.1099/jmm.0.05359-0

Levy, S., Todd, S.C. and Maecker, H.T., 1998. CD81 (TAPA-1): A molecule involved in signal transduction and cell adhesion in the immune system. Annu. Rev. Immunol., 16: 89-109. https:// doi.org/10.1146/annurev.immunol.16.1.89

Lin, X., Wang, R., Zhang, J., Sun, X., Zou, Z. and Wang, S. and Jin, M., 2015. Insights into human astrocyte response to $\mathrm{H} 5 \mathrm{~N} 1$ infection by microarray analysis. Viruses, 7: 2618-2640. https://doi.org/10.3390/ v7052618

Lin, Z., Liang. W., Kang, K., Li, H., Cao, Z. and Zhang, Y., 2014. Classical swine fever virus and $\mathrm{p} 7$ protein induce secretion of IL-1 $\beta$ in macrophages. J. Gen. Virol., 95: 2693-2699. https://doi.org/10.1099/ vir.0.068502-0

Li, R., Zhang, A., Chen, B., Teng, L., Wang, Y., Chen, H. and Jin, M., 2010. Response of swine spleen to Streptococcus suis infection revealed by transcription analysis. BMC Genomics, 11: 556. https://doi.org/10.1186/1471-2164-11-556

Liu, X., Wang, J. and Sun, G., 2015. Identification of key genes and pathways in renal cell carcinoma through expression profiling data. Kidney Blood Press. Res., 40: 288-297. https://doi. org/10.1159/000368504

Livak, K.J. and Schmittgen, T.D., 2001. Analysis of relative gene expression data using realtime quantitative PCR and the $2^{-\Delta \Delta C T}$ method. Methods, 25: 402-408. https://doi.org/10.1006/ meth.2001.1262

Lu, X., Fu, W.X., Luo, Y.R., Ding, X.D., Zhou, J.P., Liu, Y., Liu, J.F. and Zhang, Q., 2012. Genome-wide association study for T lymphocyte subpopulations in swine. BMC Genomics, 13: 488. https://doi. org/10.1186/1471-2164-13-488

Lu, X., Liu, J.F., Gong, Y.F., Wang, Z.P., Liu, Y. and Zhang, Q., 2011. Mapping quantitative trait loci for $\mathrm{T}$ lymphocyte subpopulations in peripheral blood in swine. BMC Genet., 12: 79. https://doi. org/10.1186/1471-2156-12-79

Mebius, R.E. and Kraal, G., 2005. Structure and function of the spleen. Nat. Rev. Immunol., 5: 606616. https://doi.org/10.1038/nri1669

Saalmüller, A., Reddehase, M.J., Bühring, H.J., Jonjić, S. and Koszinowski, U.H., 1987. Simultaneous expression of CD4 and CD8 antigens by a substantial proportion of resting porcine $\mathrm{T}$ 
lymphocytes. Eur. J. Immunol., 17: 1297-1301. https://doi.org/10.1002/eji.1830170912

Sandford, E.E., Orr, M., Li, X., Zhou, H., Johnson, T.J., Kariyawasam, S., Liu, P., Nolan, L.K. and Lamont, S.J., 2012. Strong concordance between transcriptomic patterns of spleen and peripheral blood leukocytes in response to avian pathogenic Escherichia coli infection. Avian Dis., 56: 732-736. https://doi.org/10.1637/10261-060512-Reg.1

Shi, Z., Sun, J., Guo, H. and Tu, C., 2009. Genomic expression profiling of peripheral blood leukocytes of pigs infected with highly virulent classical swine fever virus strain Shimen. J. Gen. Virol., 90: 16701680. https://doi.org/10.1099/vir.0.009415-0

Tarradas, J., Álvarez, B, Fraile, L., Rosell, R., Muñoz, M., Galindo-Cardiel, I., Domingo, M., Dominguez, J., Ezquerra, A., Sobrino, F. and Ganges, L., 2011. Immunomodulatory effect of swine CCL20 chemokine in DNA vaccination against CSFV. Vet. Immunol. Immunopathol., 142: 243-251. https:// doi.org/10.1016/j.vetimm.2011.05.024
Teixeira-Carvalho, A., Martins-Filho, O.A., Andrade, Z.A., Cunha-Mello, J.R., Wilson, R.A. and CorreaOliveira, R., 2002. The study of T-cell activation in peripheral blood and spleen of hepatosplenic patients suggests an exchange of cells between these two compartments in advanced human Schistosomiasis mansoni infection. Scand. J. Immunol., 56: 315-322. https://doi.org/10.1046/ j.1365-3083.2002.01133.x

Zhang, H., Wang, Y.J., Li, K., Rehman, M.U., Nabi, F., Gui, R., Lan Y.F. and Luo H.Q., 2017. Seroprevalence and pathological examination of lymphoid leukosis virus subgroup a in chickens in Anhui province, China. Pakistan J. Zool., 49: 1033-1037. http://dx.doi.org/10.17582/journal. pjz/2017.49.3.1033.1037

Zhou, C., Liu, Z., Jiang, J., Yu Y. and Zhang, Q., 2012. Differential gene expression profiling of porcine epithelial cells infected with three enterotoxigenic Escherichia coli strains. BMC Genomics, 13: 330. https://doi.org/10.1186/1471-2164-13-330 